Bangladesh J. Bot. 43(3): 323-330, 2014 (December)

\title{
ASSESSMENT OF THE GENETIC COMPONENTS AND TRAIT ASSOCIATIONS IN DIVERSE SET OF FIELDPEA (PISUM SATIVUM L.) GENOTYPES
}

\author{
AK PARIHAR*, GP Dixit, V PATHAK AND D Singh \\ Indian Institute of Pulses Research, Kanpur-208024, Uttar Pradesh, India \\ Key words: Trait associations, Cluster analysis, Genetic components
}

\begin{abstract}
One hundred and 40 genotypes of fieldpea were used to assess the genetic divergence for various agronomic traits. The study revealed that all the accessions were significantly different for the traits and a wide range of variability exists for most of the traits. Correlation studies exhibited that seed yield had positive significant correlation with most of the traits. Cluster analysis classified 140 genotypes into 12 distinct groups. A large number of genotypes (30) were placed in cluster IV followed by cluster III with 24 genotypes. The maximum inter-cluster distance was observed between clusters III and IV indicating the possibility of high heterotic effect if the individuals from these clusters are cross-bred. Principal component analysis yielded 12 Eigen vectors and PCA analysis revealed significant variations among traits with seven major principal components explaining about $90 \%$ of variations. The estimates of Eigen value associated with the principal components and their respective relative and accumulated variances explained $50.16 \%$ of total variation in the first two components. The characters with highest weight in component first were biological yield, pods/plant, yield/plant and branches/plant which explained $34.22 \%$ of the total variance. The results of principal component analysis were closely in line with those of the cluster analysis. The grouping of genotypes and hybridization among genetically diverse genotypes of different cluster would be helpful in broadening the genetic base of fieldpea and producing desirable recombinants for developing new fieldpea varieties.
\end{abstract}

\section{Introduction}

Pea (Pisum sativum L. 2n = 14, Fabaceae) is one of the most important cool season food legume crops in the world covering 6.59 million hectares (FAOSTAT 2012) and is the third most widely grown grain legume worldwide (Tyagi et al. 2012). Grains of pea are rich source of proteins, carbohydrates and other vitamins, which are good for human and livestock consumption. Dry pea grains are naturally dried ones that are consumed in soups, stews and various other cuisines.

In India, fieldpea is an important rabi pulse crop grown in about $0.76 \mathrm{~m}$ ha area with annual production of $0.71 \mathrm{~m}$ tones and productivity of $993 \mathrm{~kg} / \mathrm{ha}$ (PC Report 2012). Uttar Pradesh and Madhya Pradesh are the leading fieldpea growing state contributing 49\% of country's production. Besides these states, Bihar, Assam, Maharashtra and Orissa are also fieldpea growing states. Unfortunately, the overall yield of fieldpea is low in India as compared to the world average yield due to the narrow genetic base and limited variability used in the development of local varieties (Kumar et al. 2004). Therefore, continuous efforts are required to increase the production and productivity of field pea using diverse and exotic sources. Crop improvement depends immensely on the availability of diverse materials and their judicial utilization. Therefore, present investigation was undertaken to assess the genetic components and trait associations in diverse set of fieldpea genotypes for their utilization in crop improvement programs.

*Author for correspondence: <ashoka.parihar@gmail.com>. 


\section{Materials and Methods}

The experimental material comprised of a diverse set of 140 pea genotypes including released cultivars, local germplasm and exotic sources. The study was conducted at Research Farm of Indian Institute of Pulses Research, Kanpur, Uttar Pradesh, India. The site of experiment falls under semi arid northern plains on latitude of $26.28^{\circ}$ north and longitude of $80.21^{\circ}$ east and at an elevation of 152.4 meters above mean sea level. The soil textural class at the site was sandy loam. The accessions were grown in an augmented design with two intermittent checks 'IPF-99-25' and 'IPFD-1-10' after every 20th row. Each accession was grown in two rows of four meter length and inter- and intra row accession were kept at $60 \mathrm{~cm}$ and $30 \mathrm{~cm}$, respectively. The recommended package of practices was followed to raise the healthy crop. After eliminating the border plants, observations were recorded on five randomly chosen plants for 12 quantitative traits viz., days to flowering, days to maturity, first blossom node, number of branches/plant, plant height, number of pods/plant, pod length, number of seeds/pod, 100-seed weight, yield/plant, biological yield and harvest index. Analysis of variance (ANOVA) for augmented design was performed for all traits using statistical software SAS, version 9.3. Different analysis were performed on mean data for each trait using different statistical software viz., principal component analysis (SAS version 9.3), correlation (SPSS ver.11), biplot drawing ('R', versions 2.15) and cluster analysis (SAS version 9.3).

\section{Results and Discussion}

Analysis of variance for quantitative traits showed the significant differences among the genotypes (as mean sum of square due to treatment) for all the quantitative traits. This indicates that sufficient amount of variability was present among the genotypes for all quantitative traits. Pheno- and genotypic correlation coefficients among the 12 quantitative traits were also estimated (Table 1). Days to flowering showed positive significant geno- and phenotypic correlation with most of the traits except plant height, pod length, number of seeds/pod, 100 seed-weight and harvest index. Similarly, days to maturity had significant positive genotypic correlation with first blossom node, plant height, number of pods/plant, biological yield and yield/plant. Number of pods/plant had significant positive phenotypic and genotypic association with days to flowering, days to maturity, number of branches/plant, plant height, biological yield and yield/plant. Yield/plant exhibited highly significant positive phenotypic and genotypic correlation with days to flowering, days to maturity, number of branches/plant, plant height, number of pods/plant, 100seed-weight and biological yield. Biological yield had positive significant correlation with most of the traits except first blossom node, pod length, no. of seeds/pod and harvest index. The strong positive correlation of yield/plant with 100 seed-weight, number of branches/plant, number of pod/plant, plant height has previously been reported in fieldpea (Tyagi et al. 2012, Sardana et al. 2007, Singh and Singh 2006, Kumar et al. 2003). It suggests the possibilities of improving yield per plant by simultaneous improvement of these characters. Therefore, due emphasis is to be paid on above mentioned traits for improving the productivity during selection. The values of phenotypic correlation were in accordance with genotypic correlation suggesting due contribution of genotype in the expression of various quantitative traits.

Twelve clusters (Table 2) were formed and maximum numbers of genotypes (30) were present in cluster IV followed by cluster III with 24 genotypes. The minimum inter-cluster distance was 4.40 units between cluster II and VI and maximum inter-cluster distance (190.84 units) was between cluster III and IV. Genotypes from clusters which had more inter-cluster distance could be crossed for creation of maximum variability for effective selection of 


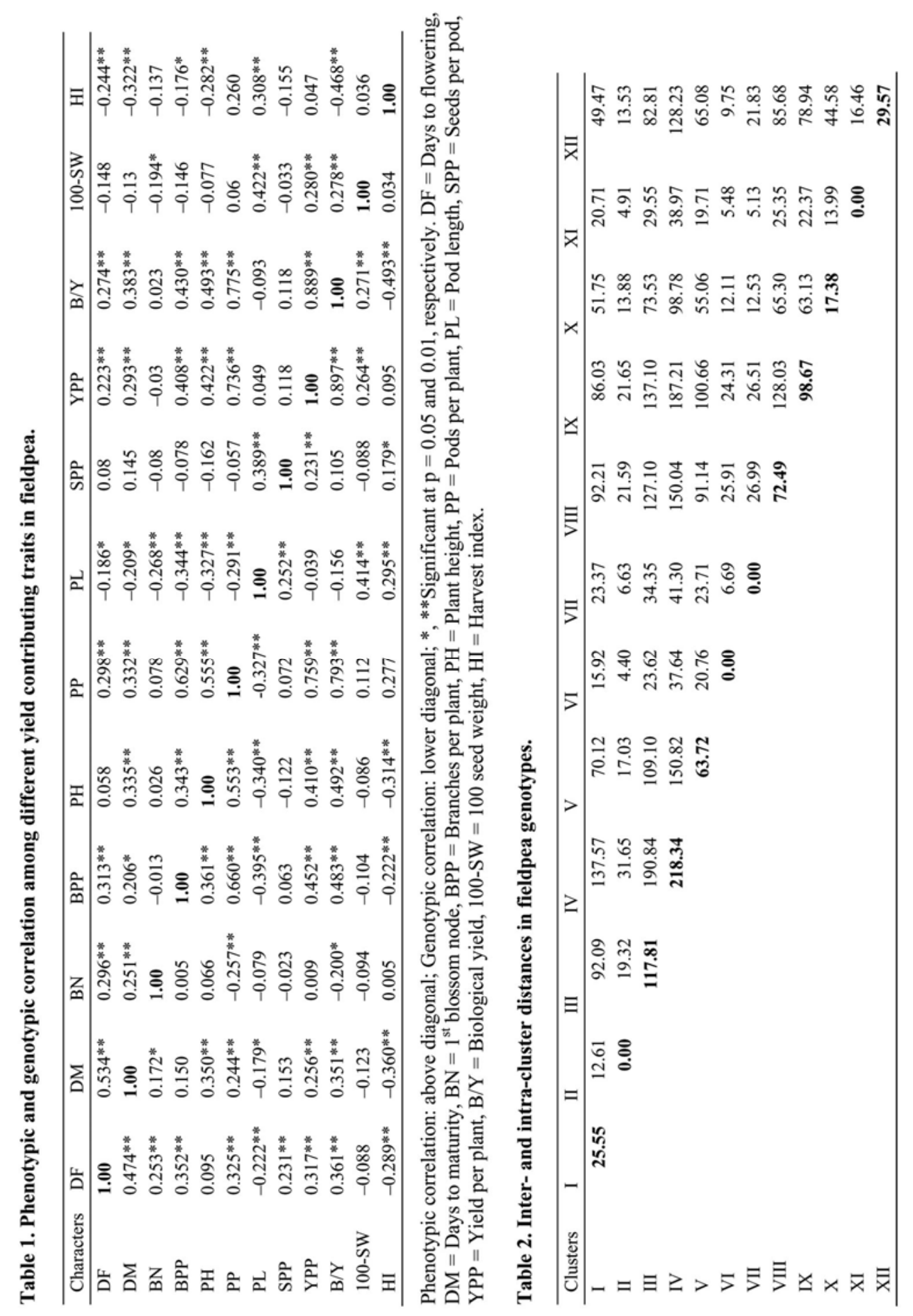




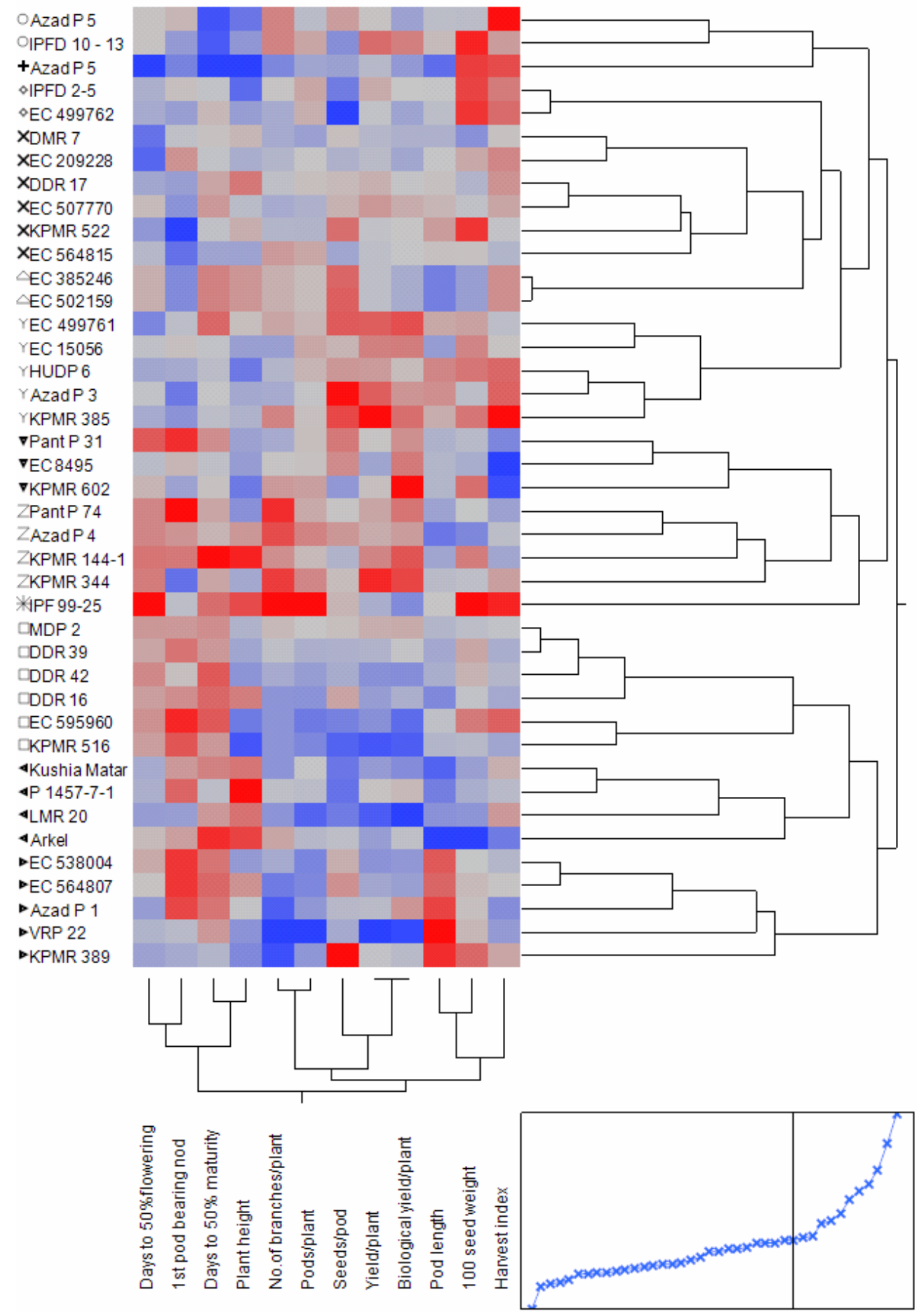

Fig. 1. Dendogram showing 41 genotypes drawn 12 clusters using PPS SRS technique. 
transgressive segregants. The minimum intra-cluster distance was found in cluster II and XI (0.0 unit) each having one genotype, whereas the maximum intra-cluster distance was in cluster IV (218.34 unit) having 8 genotypes. The genotypes of cluster IV were diverse indicating that there is opportunity of improvement through selection within cluster. The grouping of pea genotypes in different cluster has been reported by earlier workers (Dixit et al. 2002, Singh and Singh 2003, Tiwari et al. 2004). For the ease of presentation of genotypes through two way dendogram using Ward's method (Ward 1963) the original dendogram produced for 140 accessions were redrawn using 41 genotypes. These 41 genotypes were selected from each of the 12 clusters through Probability Proportional to Size Simple Random Sampling (PPS SRS) technique so as to obtain a true representation of original dendogram (Fig. 1). Two way dendogram showed the grouping of genotypes on the basis of yield contributing traits and vice-versa. The color intensity of dendogram depicts different groups on the basis of variability within the particular trait or genotype. Inter crossing among divergent genotypes of different clusters may generate large variability that would produce desirable recombinants for yield and yield attributes for developing new fieldpea varieties with broad genetic base (Sardana et al. 2007).

Genotypes of the same region were distributed in more than one cluster as also the cultivars of the heterogeneous origin were grouped in the same cluster. It indicated that there was no relationship between the genetic diversity and geographical origin of genotypes under study. Thus there was no parallelism between genetic and geographical diversity.

In principal component analysis, the variance-covariance matrix was used to transform all the quantitative attributes into a single index of similarity in the form of principal component, which yielded 12 Eigen value for 12 Eigen vectors but we discussed only seven Eigen vectors, as first seven principal components accounted for more than $89 \%$ variation. The estimates of Eigen value associated with the principal component and their respective relative and accumulated variances explained 50.16 percentage of the total variation in the two first principal components indicating a high degree of correlation among the characters for the genotypes analyzed. Percentages of variation attributable to the first two components by decreasing order were 34.22 and 15.94 . Most of the variation was distributed up to the 7th principal component, being responsible for $89.10 \%$ of the relative variation observed (Table 3). By examining the Eigen vectors of individual components, indication may be obtained about their level of association with the original traits. The characters with highest weight in component first were biological yield, number of pods/plant, yield/plant, and number of branches/plant which explained $34.22 \%$ of the total variance. Component 2 was associated with 100 seed-weight, pod length, yield/plant, biological yield and number of seeds/pod which account for $15.94 \%$ of the variance. In the component 3 , traits with highest weight were number of seeds/pod, days to $50 \%$ flowering, days to maturity and pod length which explained $11.74 \%$ of the total variance. Similarly, the characters with the highest weight in component 4 were harvest index, number of branches/plant, number of seeds/pod and number of pod/plant (9.34\%), component 5 with first blossom node, 100-seed weight, harvest index and yield/plant (7.59\%); component 6 with plant height, harvest index, first blossom node and days to maturity (6.25\%) and component 7 with harvest index, days to maturity, days to flowering and 100 -seed weight (4.54\%) (Tables 3 and 4). Yield and some yield contributing traits appear strongly in the first three components (Katiyar and Dixit 2009). The relationship between different yield contributing traits and genotypes behavior is plotted in the biplot graph (Fig. 2). The biplot provides a useful tool for data analysis. If the angle and directions between vectors or lines which indicated yield contributing traits are less than $90^{\circ} \mathrm{C}$, it represents a positive correlation and if the angle between the lines is more than $90^{\circ} \mathrm{C}$, it indicates negative correlation. According to the biplot, there was a positive correlation between most of the traits that appeared in graph close to each other confirming the simple correlation results. 
Table 3. Eigen values, proportional and cumulative per cent variation and principal component for 12 yield contributing traits.

\begin{tabular}{lclc}
\hline $\begin{array}{l}\text { Principal } \\
\text { component }\end{array}$ & $\begin{array}{l}\text { Eigen } \\
\text { value }\end{array}$ & $\begin{array}{l}\text { Proportional } \\
\text { per cent }\end{array}$ & $\begin{array}{c}\text { Cumulative } \\
\text { per cent }\end{array}$ \\
\hline 1 & 4.11 & $34.224 \square$ & 34.22 \\
2 & 1.91 & 15.941 & 50.16 \\
3 & 1.41 & $11.745 \square$ & 61.91 \\
4 & 1.12 & $9.342 \square$ & 71.25 \\
5 & 0.91 & $7.596 \square$ & 78.85 \\
6 & 0.75 & $6.255 \square$ & 85.10 \\
7 & 0.54 & $4.537 \square$ & 89.64 \\
8 & 0.39 & $3.264 \square$ & 92.90 \\
9 & 0.34 & $2.866 \square$ & 95.77 \\
10 & 0.33 & $2.752 \square$ & 98.52 \\
11 & 0.17 & $1.385 \square$ & 99.91 \\
12 & 0.01 & $0.094 \square$ & 100 \\
\hline
\end{tabular}

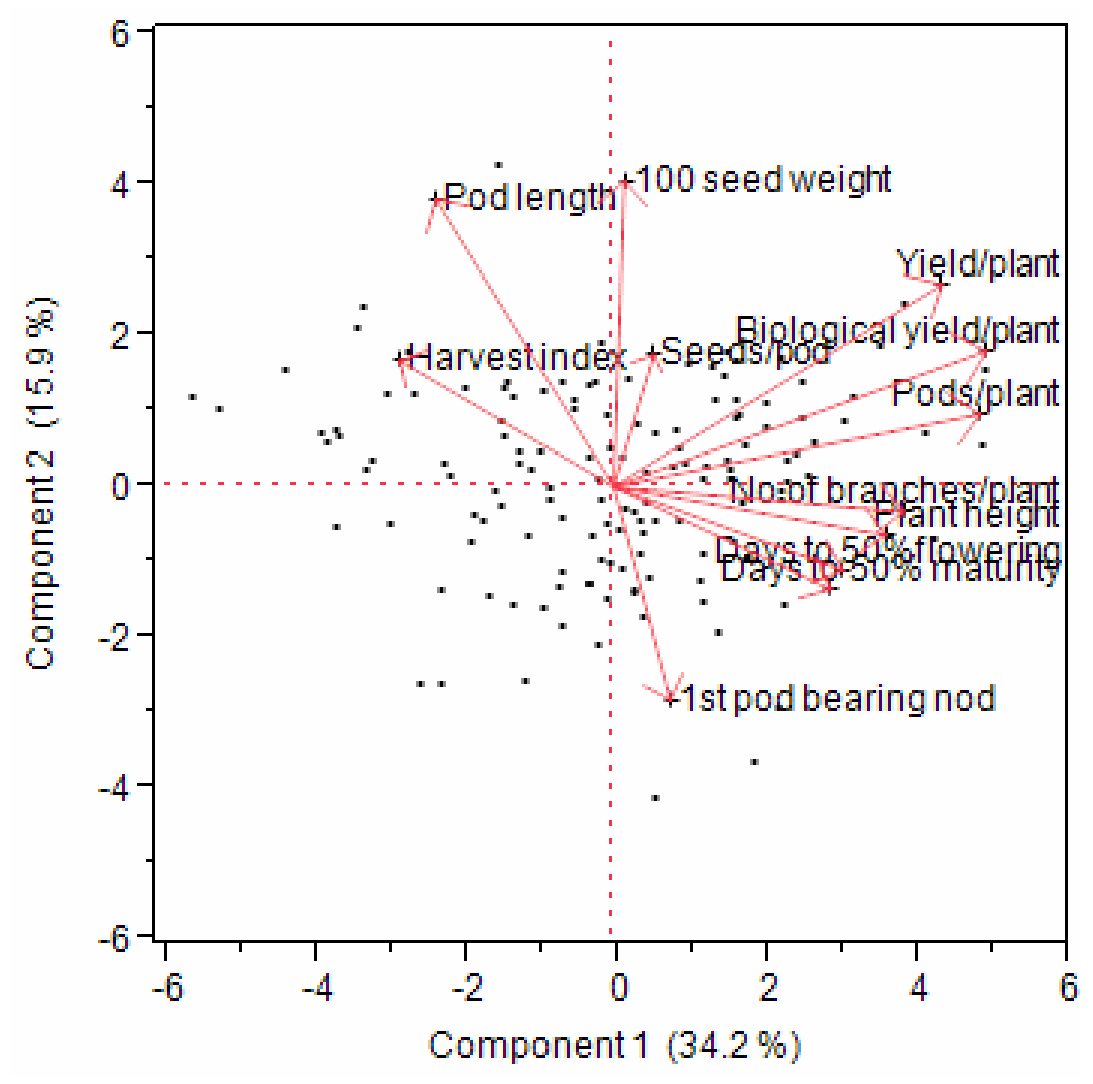

Fig. 2. The biplot of 140 accession of fieldpea based on PC1 and PC2. 
Thus the present investigation revealed that there exists a wide range of variation in various yield contributing traits in the diverse set of pea genotypes studied. Significant correlations were observed among the traits with seed yield having significant positive correlation to most of the traits suggesting indirect selection based on components traits will help in improving the seed yield in fieldpea. PCA analysis revealed significant variations among traits with seven major principal components explaining $89.64 \%$ of variations. Cluster analysis classified the genotypes in

Table 4. Estimates of the weighting coefficient (Eigen vector) associated with the principal components and different characters of fieldpea.

\begin{tabular}{lrrrrrrr}
\hline Characters & \multicolumn{7}{c}{ Eigen vectors } \\
\cline { 2 - 8 } & PC 1 & PC 2 & PC 3 & PC 4 & PC 5 & PC 6 & PC 7 \\
\hline Days to 50\% flowering & 0.27 & -0.14 & 0.47 & -0.14 & 0.14 & -0.38 & 0.39 \\
Days to 50\% maturity & 0.26 & -0.18 & 0.34 & -0.37 & -0.34 & 0.28 & 0.40 \\
First blossom node & 0.07 & -0.37 & 0.20 & -0.17 & 0.72 & 0.36 & -0.25 \\
Branches/plant & 0.34 & -0.04 & -0.07 & 0.42 & 0.06 & -0.40 & 0.15 \\
Plant height & 0.32 & -0.08 & -0.29 & 0.04 & -0.32 & 0.53 & 0.09 \\
Pods/plant & 0.43 & 0.12 & -0.12 & 0.19 & 0.15 & 0.04 & -0.04 \\
Pod length & -0.21 & 0.49 & 0.21 & -0.23 & -0.07 & 0.11 & -0.10 \\
Seeds/pod & 0.05 & 0.23 & 0.65 & 0.29 & -0.22 & 0.05 & -0.39 \\
Yield/plant & 0.39 & 0.35 & 0.05 & 0.10 & 0.15 & 0.18 & -0.03 \\
Biological yield/plant & 0.44 & 0.23 & -0.06 & -0.14 & 0.04 & 0.00 & -0.25 \\
100-seed weight & 0.01 & 0.52 & -0.18 & -0.41 & 0.28 & -0.12 & 0.28 \\
Harvest index & -0.25 & 0.22 & 0.14 & 0.51 & 0.25 & 0.38 & 0.54 \\
\hline
\end{tabular}

12 distinct clusters. Further, it may be concluded that selection of genotypes from diverse group and their involvement in hybridization programme will maximize opportunities to obtain transgressive segregants or recombinants as there is a higher chance from such genotypes to contribute unique desirable alleles at various loci. The grouping of genotypes and hybridization among genetically diverse genotypes from different cluster would be helpful in broadening the genetic base of pea and producing desirable recombinants for developing new fieldpea varieties. Also, these results can be used by the breeders to develop new breeding protocols in future fieldpea improvement.

\section{References}

Dixit GP, Singh IP and Khare AP 2002. Genetic divergence study in fieldpea. Legume Res. 25:199-201.

FAOSTAT 2012. Statistical Database of the Food and Agriculture of the United Nations. http://www.fao.org.

Kumar B, Ram L, Singh JD and Singh B 2003. Correlation and path coefficient analysis in pea (Pisum sativum L.). Progr. Agri. 3:141-142.

Kumar S, Gupta S, Chandra S and Singh BB 2004. How wide is the genetic base of pulse crops? In: Masood Ali, B.B.Singh, Shiv Kumar and Vishwa Dhar (eds), Pulses in new perspective. Indian Society of Pulses Research and Development. IIPR, Kanpur, India. pp. 211-221.

Katiyar PK and Dixit GP 2009. Multivariate analysis for genetic divergence in fieldpea (Pisum sativum) germplasm. Indian J. Agri. Sci. 79(3): 181-183.

PC Report 2012. Project coordinator report, AICRP on MULLaRP, IIPR, Kanpur, India.

Sardana S, Mahajan RK, Gautam NK and Ram B 2007. Genetic variability in pea (Pisum sativum L.) germplasm for utilization. SABRAO J. Breed. Genet. 39(1): 31-42 
Singh JD and Singh IP 2006. Genetic variability, heritability, expected genetic advance and character association in fieldpea (Pisum sativum L.). Legume Res. 29(1): 65-67.

Singh G and Singh SP 2003. Genetic divergence in fieldpea (Pisum sativum L.) Legume Res. 26: 131-133.

Tiwari SK, Kumar R, Singh HL and Katiyar, RP 2004. Genetic diversity analysis in pea (Pisum sativum L.). Indian J. Agric. Res. 38(1): 60-64

Tyagi N, Singh AK, Rai VP, Kumar S and Srivastava CP 2012. Genetic variability studies for lodging resistance and yield attributes in pea (Pisum Sativum L.). J. Food Legumes 25(3):179-182.

Ward JH 1963. Hierarchical grouping to optimize an objective funtcion. J. Am. Stat. Assoc. 58: 236-244.

(Manuscript received on 11 December, 2013; revised on 23 February, 2014) 